\title{
Does the body adiposity index (BAI) apply to paediatric populations?
}

\author{
T. El Aarbaoui ${ }^{1,2}$, H. Samouda ${ }^{3}$, D. Zitouni ${ }^{1,4}$, C. di Pompeo ${ }^{1,2}$, C. de Beaufort ${ }^{5}$, F. Trincaretto ${ }^{6}$, A. Mormentyn ${ }^{7}$, \\ H. Hubert ${ }^{1,2}$, M. Lemdani ${ }^{1,4}$, and B. C. Guinhouya ${ }^{1,2}$
}

${ }^{1}$ EA 2694, Laboratory of Public Health, UDSL, University Lille-Northern France, Lille, France, ${ }^{2}$ Faculty of Health Engineering and Management, UDSL/ ILIS, University Lille-Northern France, Loos, France, ${ }^{3}$ Centre for Health Studies, Department of Public Health, Centre de Recherche Public en Santé (CRP-Santé), Strassen, Grand-Duchy of Luxembourg, ${ }^{4}$ Faculty of Biological and Pharmaceutical Sciences, Department of Biomathematics, University Lille-Northern France, Lille, France, ${ }^{5}$ DECCP, Centre Hospitalier de Luxembourg, Grand-Duchy of Luxembourg, ${ }^{6}$ Department of Public Health of the City Council Maubeuge Val de Sambre, Maubeuge, France, and ${ }^{7}$ IFSI, Nursing Training Institute of Maubeuge, Maubeuge, France

\begin{abstract}
Objective: Validation of body adiposity index (BAI) in a paediatrics sample; and to develop, if necessary, a valid BAl for paediatrics (i.e. BAl $\mathrm{p}_{\mathrm{p}}$ ).

Methods: A total of 1615 children (52\% boys) aged 5-12 years underwent anthropometry. Their body composition was assessed using a foot-to-foot bioimpedance. The validity of BAI = (Hip circumference/Height ${ }^{1.5}$ ) -18 was tested by combining correlation and agreement statistics. Then, the sample was split into two sub-samples for the construction of $\mathrm{BAI}_{\mathrm{p}}$. A regression was used to compute the prediction equation for $\mathrm{BAl}_{\mathrm{p}}$-based percentage of body fat (\%BF). Results: The initial BAl over-estimated the \%BF of children by $49 \%(29.6 \pm 4.2 \%$ versus $19.8 \pm 6.8 \% ; p<0.0001)$. The original methodology led to a $B A I_{p}=\left(\right.$ Hip circumference/Height $\left.{ }^{0.8}\right)$ -38 in children. When compared to $\mathrm{BAl}, \mathrm{BAl}$ p showed both better correlation $(r=0.57 ; p<0.01$ versus $r=0.74 ; p<0.0001)$ and agreement $(\mathrm{ICC}=0.34 ;[95 \% \mathrm{Cl}=-0.19-0.65]$ versus $\mathrm{ICC}=0.83$; $[95 \% \mathrm{Cl}=0.81-0.84])$. However, there were some systematic biases between the two values of $\% \mathrm{BF}$ as exemplified by the large $95 \%$ limit of agreement [-9.1\%; $8.8 \%]$ obtained.

Conclusion: $\mathrm{BAl}$ over-estimates the $\% \mathrm{BF}$ in children. In contrast, $\mathrm{BAI}_{\mathrm{p}}$ appears as a new index for children's body fatness, with acceptable accuracy. In its current form, this index is valid only for large-scale studies.
\end{abstract}

\section{Keywords}

Bioelectrical impedance, body composition, childhood obesity

\section{History}

Received 23 November 2012

Revised 3 April 2013

Accepted 26 April 2013

Published online 18 June 2013

\section{Introduction}

Over the last few decades the prevalence of childhood overweight and obesity has increased dramatically. About 170 million children (aged $<18$ years) are estimated to be overweight worldwide (Lobstein et al., 2004) and in many countries, including Canada, France, Germany, Japan, the UK and the US, the number of overweight children has at least doubled since 1970 (Han et al., 2010). Aside from research that has shown that childhood obesity is likely to track into adulthood (Serdula et al., 1993; Whitaker et al., 1997), the health consequences of obesity are substantial, including long-lasting morbidities and an increased risk of premature mortality (WHO, 2009). Thus, despite cumulative data suggesting a levelling off in the prevalence of childhood obesity (Olds et al., 2011), public health endeavours should be continued in order to curb the current epidemic. In order to be effective, these prevention strategies need to be based on an accurate assessment of body fatness in young people.

Correspondence: C. Benjamin Guinhouya, PhD, MPH, EA 2694, Laboratory of Public Health \& Faculty of Health Engineering and Management, UDSL/ILIS, University Lille-Northern France, 42, rue Ambroise Paré, F-59120 Loos, France. Tel: +33 (3) 206237 37. Fax: +33 (3) 206237 38. E-mail: benjamin.guinhouya@univ-lille2.fr
Basically, obesity is defined as an excessive accumulation of fat in the body (OMS, 2003). It is often assessed by body mass index (BMI), with internationally defined standards (Cole et al., 2000; de Onis et al., 2007) for the classification of young people. Nevertheless, the use of BMI as a surrogate of body fat or adiposity in children raises a number of issues (Hall \& Cole, 2006). Importantly, BMI is unable to differentiate fat mass from fat free mass, especially in the growing body of a child (Neovius et al., 2004; McCarthy et al., 2006). On the other hand, laboratory-based methods such as dual energy X-ray absorptiometry (DEXA), computed tomography, underwater weighing or magnetic resonance imaging (MRI) provide a reproducible and accurate measurement of body composition. However, body fat is difficult and expensive to measure directly in large samples using these sophisticated techniques. Alternative less-expensive, simple and reproducible anthropometric measurements such as waistto-hip ratio (WHR), waist circumference (WC) and waist-to-e height ratio (WHtR) have been associated with cardiometabolic comorbidities in young people, beyond BMI (Gillum, 1999; McCarthy, 2006; Browning et al., 2010; Taylor et al., 2011).

Because measures of body fat, even if they are indirect, may be better than BMI (Cole et al., 2000), there still remains 
a need to provide a cheap and easy-to-use tool for children in large-scale studies. In adults, Bergman et al. (2011) recently proposed the body adiposity index (BAI), which is an anthropometry-based (i.e. height and hip circumference) formula to estimate body fat. BAI is currently under investigation and debates regarding its superiority to BMI as well as its relationships with various health outcomes are ongoing (Elisha et al., 2013; Freedman et al., 2012; GodoyMatos et al., 2012; Hung et al., 2012; López et al., 2012; Schulze et al., 2012; Snijder et al., 2012). However, unlike BMI, BAI has not been extended to, or tested in, paediatrics. If BAI is to be used to determine the percentage of fat in children, it should first provide similar results regarding any other measure of their body fat. Additionally, all assumptions underlying the development of BAI in adults should also apply to young people.

Therefore, the aim of the present study is 2-fold: (1) to test the validity of BAI in a paediatric population; and (2) to develop, if necessary, a valid BAI for children.

\section{Materials and methods}

\section{Subjects}

Children were recruited from public primary schools and kindergarten of two Education Authority Areas in the Northern France (School districts of Lille and Avesnes-Val de Sambre). A total of 1615 children aged 5-12 years were involved in a series of cross-sectional studies implemented during several periods located between September 2005 and May 2009. The sample encompasses pre-school- and schoolaged children from 30 schools out of a possible total of 54 schools (i.e. recruitment rate of $56 \%$ at the school level). A participation rate of $35 \%$ with an equal distribution between genders was obtained at children level. Schools engaged in this protocol were only those whose head of school were willing to participate. In these schools, all children was invited to participate and only those whose parents provided written informed consent were included. The study received the approval of the local advisory board of Lille. All participants underwent anthropometric and body composition assessments, which were performed by the same trained examiners.

\section{Anthropometric and body fat measurement}

Height was measured to the nearest $0.1 \mathrm{~cm}$ with a stadiometer (Seca 214, Hamburg, Germany). The complete stature was defined as the maximal distance from the floor to the vertex of the head. For measurements, children were standing without shoes with their body stretched upward and their head in the Frankfurt plane (Lohmann et al., 1988). Body mass was measured and recorded to the nearest $0.1 \mathrm{~kg}$ with an in-built bioelectrical impedance analysis (BIA) used as a weight scale and body mass index (BMI) was calculated as body mass in kilograms divided by the square of height in metres $\left(\mathrm{kg} / \mathrm{m}^{2}\right)$. Hip circumference (HC) was recorded at the maximum circumference over the buttocks to the nearest $1 \mathrm{~mm}$.

The percentage of body fat (\%BF) of each child was recorded to the nearest $0.1 \%$ using a single frequency $(50 \mathrm{kHz}$, $90 \mu \mathrm{A}$ ) foot-to-foot Tanita body composition analyser BC-420
MA (Tanita Corp., Tokyo, Japan) (Lloret Linares et al., 2011). An in-built equation by the manufacturer allowed the calculation of body composition on the basis of the body resistance index. Furthermore, the $\% \mathrm{BF}$ of each child was also independently estimated through BAI provided by Bergman et al. (2011) using the following equation:

$$
\begin{aligned}
& \text { \%Adiposity }\left(\% \mathrm{BF}_{\text {predicted }}\right)=\mathrm{BAI}-18 ; \\
& \text { with } \mathrm{BAI}=\frac{\mathrm{HC}(\mathrm{cm})}{\operatorname{Height}(\mathrm{m})^{1.5}}
\end{aligned}
$$

\section{Statistical analysis and construction of BAI for paediatrics $\left(\mathrm{BAl}_{\mathrm{p}}\right)$}

Descriptive data are expressed as mean \pm standard deviation. Gender differences were examined using unpaired Student's $t$-tests. To determine whether the original BAI (Bergman et al., 2011) could be applied to paediatrics, the predicted $\% \mathrm{BF}$ was compared to the actual \%BF using Student's $t$-tests for matched pairs, Pearson's product moment coefficients of correlation and the intra-class coefficient of correlation (ICC) for absolute agreement. The agreement between the two values of \% BF was then checked using a Bland \& Altman (1999) plot.

For the construction of $\mathrm{BAI}_{\mathrm{p}}$, the initial sample was split into two sub-groups ( $\mathrm{A}$ and $\mathrm{B}$ ) using a random sampling technique. In this instance, a target of 50\% was set to determine whether a given child should be placed in subgroup A or B. Bergman et al.'s (2011) procedure, for the development of the initial BAI in adults, was applied to subgroup A in extenso, beginning with the acceptance of the formalism as follows:

$$
\mathrm{BAI}_{\mathrm{p}}=\frac{\mathrm{HC}(\mathrm{cm})}{\operatorname{Height}(\mathrm{m})^{x}}
$$

In this equation, $x$ denotes a unitless power term, defined as the value exhibiting the highest coefficient of correlation between $\mathrm{BAI}_{\mathrm{p}}$ and the actual $\% \mathrm{BF}$. Once determined, $\mathrm{BAI}_{\mathrm{p}}$ was regressed onto the actual $\% \mathrm{BF}$ in order to obtain the intercept and slope for the new prediction equation of $\% \mathrm{BF}$, valid for children. Rounding off and other formal adjustments, for example combining Lin's (1989) concordance coefficient of correlation (CCC) with Bland \& Altman (1999) pairwise comparison, were performed as appropriate to obtain the final equation. The intercept was obtained by regressing $\mathrm{BAI}_{\mathrm{p}}$ onto the actual \%BF. Then, the possible different values of the intercept were compared for their CCC, by keeping constant both the correlation coefficient and slope of the first equation. The intercept that provided the highest CCC was used for the final equation.

The prediction equation obtained from sub-group A was then used to predict the \% $\mathrm{BF}$ of children in sub-group $\mathrm{B}$. The $\% \mathrm{BF}$ predicted in this way was further compared to the actual $\% \mathrm{BF}$ using a matched pairs Student's $t$-test. The final $\mathrm{BAI}_{\mathrm{p}}$ based formula to predict $\% \mathrm{BF}$ was developed using the pooled data from sub-groups $\mathrm{A}$ and $\mathrm{B}$. This equation was crossvalidated in each sub-group by taking into account a potential gender effect. A residual analysis was further carried out to check for the assumptions of normality and homoscedasticity. 
Table 1. General characteristics of children (values are expressed in mean $\pm \mathrm{SD}$ ).

\begin{tabular}{|c|c|c|c|c|c|c|}
\hline & Age (years) & Body mass $(\mathrm{Kg})$ & Height $(\mathrm{cm})$ & BMI $\left(\mathrm{kg} / \mathrm{m}^{2}\right)$ & $\mathrm{HC}(\mathrm{cm})$ & $\mathrm{BF}(\%)$ \\
\hline \multicolumn{7}{|l|}{ Group A } \\
\hline Boys $(n=434)$ & $8.7 \pm 1.8$ & $31.3 \pm 8.9$ & $132.9 \pm 10.3$ & $17.4 \pm 3.0$ & $72.4 \pm 8.6$ & $18.2 \pm 6.2$ \\
\hline Girls $(n=404)$ & $8.6 \pm 1.7$ & $31.9 \pm 9.6$ & $132.8 \pm 11.2$ & $17.7 \pm 3.1$ & $73.4 \pm 9.0$ & $21.9 \pm 7.1^{*}$ \\
\hline Sample A $(n=838)$ & $8.6 \pm 1.7$ & $31.6 \pm 9.3$ & $132.8 \pm 10.7$ & $17.6 \pm 3.1$ & $72.8 \pm 8.8$ & $20.0 \pm 6.9$ \\
\hline \multicolumn{7}{|l|}{ Group B } \\
\hline Boys $(n=407)$ & $8.6 \pm 1.7$ & $31.3 \pm 9.4$ & $132.8 \pm 10.8$ & $17.4 \pm 3.1$ & $72.6 \pm 8.9$ & $18.0 \pm 6.3$ \\
\hline Girls $(n=370)$ & $8.7 \pm 1.6$ & $31.7 \pm 9.0$ & $133.3 \pm 11.0$ & $17.5 \pm 2.9$ & $73.0 \pm 8.3$ & $21.4 \pm 6.7^{*}$ \\
\hline Sample B $(n=777)$ & $8.6 \pm 1.7$ & $31.5 \pm 9.2$ & $133.0 \pm 10.9$ & $17.4 \pm 3.0$ & $72.8 \pm 8.6$ & $19.6 \pm 6.7$ \\
\hline \multicolumn{7}{|l|}{ Total sample } \\
\hline Boys $(n=841)$ & $8.6 \pm 1.7$ & $31.3 \pm 9.2$ & $132.8 \pm 10.5$ & $17.4 \pm 3.0$ & $72.5 \pm 8.7$ & $18.1 \pm 6.2$ \\
\hline Girls $(n=774)$ & $8.6 \pm 1.7$ & $31.8 \pm 9.3$ & $133.0 \pm 11.1$ & $17.6 \pm 3.0$ & $73.2 \pm 8.7$ & $21.7 \pm 6.9^{*}$ \\
\hline Total $(n=1615)$ & $8.6 \pm 1.7$ & $31.5 \pm 9.2$ & $132.9 \pm 10.8$ & $17.5 \pm 3.0$ & $72.8 \pm 8.7$ & $19.8 \pm 6.8$ \\
\hline
\end{tabular}

BMI, body mass index; HC, hip circumference; BF, body fat.

$*$ Denotes a significant difference between boys and girls, $p<0.0001$.

Durbin-Watson's statistic was used to test the autocorrelation of the residuals.

\section{Results}

\section{General characteristics of the sample}

As shown in Table 1, the sample included 841 boys and 774 girls, aged $8.6 \pm 1.7$ years. Their mean body mass, height, $\mathrm{BMI}, \mathrm{HC}$ and $\% \mathrm{BF}$ were $31.5 \pm 9.2 \mathrm{~kg}, 132.9 \pm 10.8 \mathrm{~cm}$, $17.5 \pm 3.0 \mathrm{~kg} / \mathrm{m}^{2}, 62.6 \pm 8.7 \mathrm{~cm}$ and $19.8 \pm 6.8 \%$, respectively. Apart from $\% \mathrm{BF}$, where a significant difference was found between boys $(18.1 \pm 6.3 \%)$ and girls $(21.7 \pm 6.9 \%)$ in the whole sample, as well as in sub-groups A $(18.2 \pm 6.2 \%$ versus $21.9 \pm 7.1 \%$, respectively) and $\mathrm{B}(18.0 \pm 6.3 \%$ versus $19.6 \pm 6.7 \%$, respectively) $(p<0.0001$ in each case), no further gender differences were obtained between or within sub-groups (Table 1).

\section{Application of the original BAI to children}

When the initial BAI was used to predict the $\% \mathrm{BF}$ of children in the current sample, it translated into a mean $\% \mathrm{BF}$ of $29.6 \pm 4.2 \%$. This value was $\sim 49 \%$ higher than the actual $\%$ BF of $19.8 \pm 6.8 \%(p<0.0001)$. Furthermore, a moderate coefficient of correlation $(r=0.57, p<0.01)$ and a poor agreement ( $\mathrm{ICC}=0.34 ; 95 \%$ confidence interval $[\mathrm{CI}]:-0.19$; $0.65)$ were obtained between the two values of $\% \mathrm{BF}$. Moreover, as displayed in Figure 1, the mean bias between the two values of $\% \mathrm{BF}$ was $-10 \%$, with a $95 \%$ limit of agreement of $[-21.0 \% ; 1.0 \%]$, which denote a substantial lack of agreement between the two values and an over-estimation of $\% \mathrm{BF}$ as predicted using BAI.

\section{Construction of $\mathrm{BAI}_{\mathrm{p}}$ and validity of the predicted $\% \mathrm{BF}$}

Let us remember that the first step in the determination of $\mathrm{BAI}_{\mathrm{p}}$ is based on the knowledge of the $x$ term that maximizes the correlation between the ratio $\mathrm{HC} / \mathrm{Height}^{x}$ and the actual bioimpedance-based \%BF. As shown in Figure 2, the suitable $x$ term for children was equal to 0.8 for a correlation coefficient of 0.74 . This value was consistent throughout the sub-groups as well as the whole sample (Figure 2). It is noteworthy that, in this figure, for a power term $x$ of 1.5 , a weaker correlation coefficient of 0.56 was obtained. Thus, $\mathrm{BAI}_{\mathrm{p}}$ should be written:

$$
\mathrm{BAI}_{\mathrm{p}}=\frac{\mathrm{HC}(\mathrm{cm})}{\operatorname{Height}(\mathrm{m})^{0.8}} .
$$

The linear regression of $\mathrm{BAI}_{\mathrm{p}}$ onto the actual \% $\mathrm{BF}$ led to the following raw formulae in the two sub-groups (Table 2).

$$
\text { Group A : \% } \begin{aligned}
\mathrm{BF}_{\text {predicted }} & =1.055 \times \mathrm{BAI}_{\mathrm{p}}-41.159 ; \\
R^{2} & =0.55, \quad \mathrm{SEE}=4.64 .
\end{aligned}
$$

$$
\text { Group B : } \% \mathrm{BF}_{\text {predicted }}=1.036 \times \mathrm{BAI}_{\mathrm{p}}-40.336 \text {; }
$$$$
R^{2}=0.56, \quad \mathrm{SEE}=4.47 .
$$

Because of roughly similar prediction equations in the two sub-groups, data from these sub-groups were pooled to express the final prediction equation as follows:

$$
\begin{aligned}
\% \mathrm{BF}_{\text {predicted }} & =1.046 \times \mathrm{BAI}_{\mathrm{p}}-40.779 ; \\
R^{2} & =0.55, \quad \mathrm{SEE}=4.56 .
\end{aligned}
$$

Since the slope of this equation was close to 1 , it was set at exactly 1 . Then, on the basis of the best adjustment combining the bias correction factor $\left(\mathrm{C}_{\mathrm{b}}\right)$ and $\mathrm{CCC}$, an intercept of -38 was obtained (for $\mathrm{C}_{\mathrm{b}}=0.94$ and $\mathrm{CCC}=0.70$ ). Thus, Equation (6) became:

$$
\begin{aligned}
\% \mathrm{BF}_{\text {predicted }} & =\mathrm{BAI}_{\mathrm{p}}-38 ; \\
R^{2} & =0.55, \quad \mathrm{SEE}=4.56 .
\end{aligned}
$$

The different formulae showed a similar level of adequacy when cross-validated on each sub-group and on the whole sample (Table 2). The use of $\mathrm{BAI}_{\mathrm{p}}$ on the current sample translated into a mean \% BF of $19.9 \pm 4.8 \%$ $($ Boys $=19.7 \pm 4.9 \%$ versus Girls $=20.2 \pm 4.7 \%, p=0.03$ ). This predicted mean $\% \mathrm{BF}$ was only marginally different from the actual \% BF $(-0.1 \pm 4.6 \% ; \Delta=0.5 \%, p=0.28)$. A high coefficient of correlation $(r=0.74, p<0.0001)$ and an excellent agreement (ICC $=0.83 ; 95 \% \mathrm{CI}=0.81 ; 0.84)$ were found between the predicted $\% \mathrm{BF}$ using $\mathrm{BAI}_{\mathrm{p}}$ and the actual $\% \mathrm{BF}$. The Bland and Altman plot in Figure 3 displays a better agreement between the actual $\% \mathrm{BF}$ and the predicted $\% \mathrm{BF}$ 


\section{T. El Aarbaoui et al.}

Figure 1. Bland and Altman pairwise comparison between the actual and the estimated percentage of body fat using the original body adiposity index (BAI).

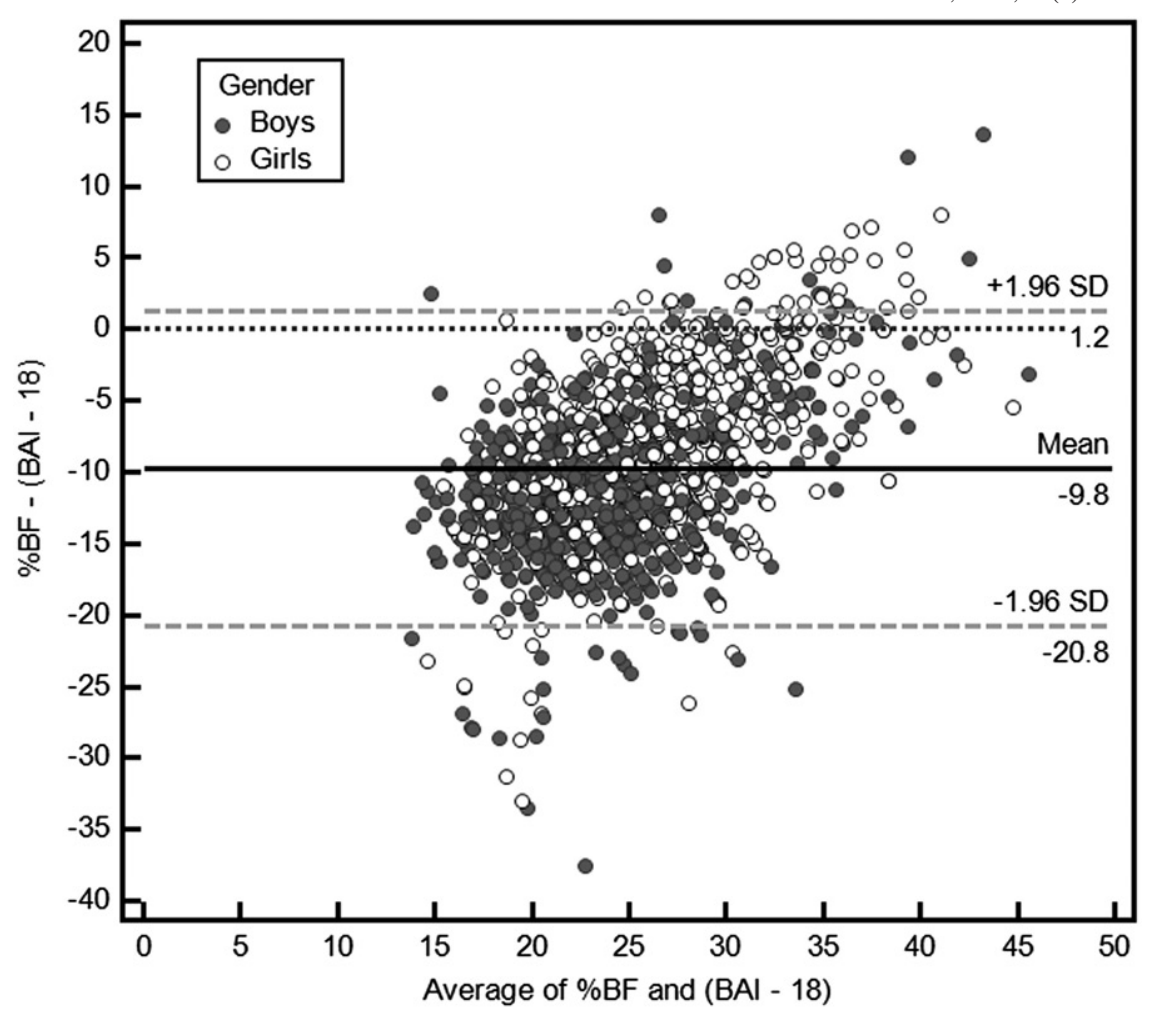

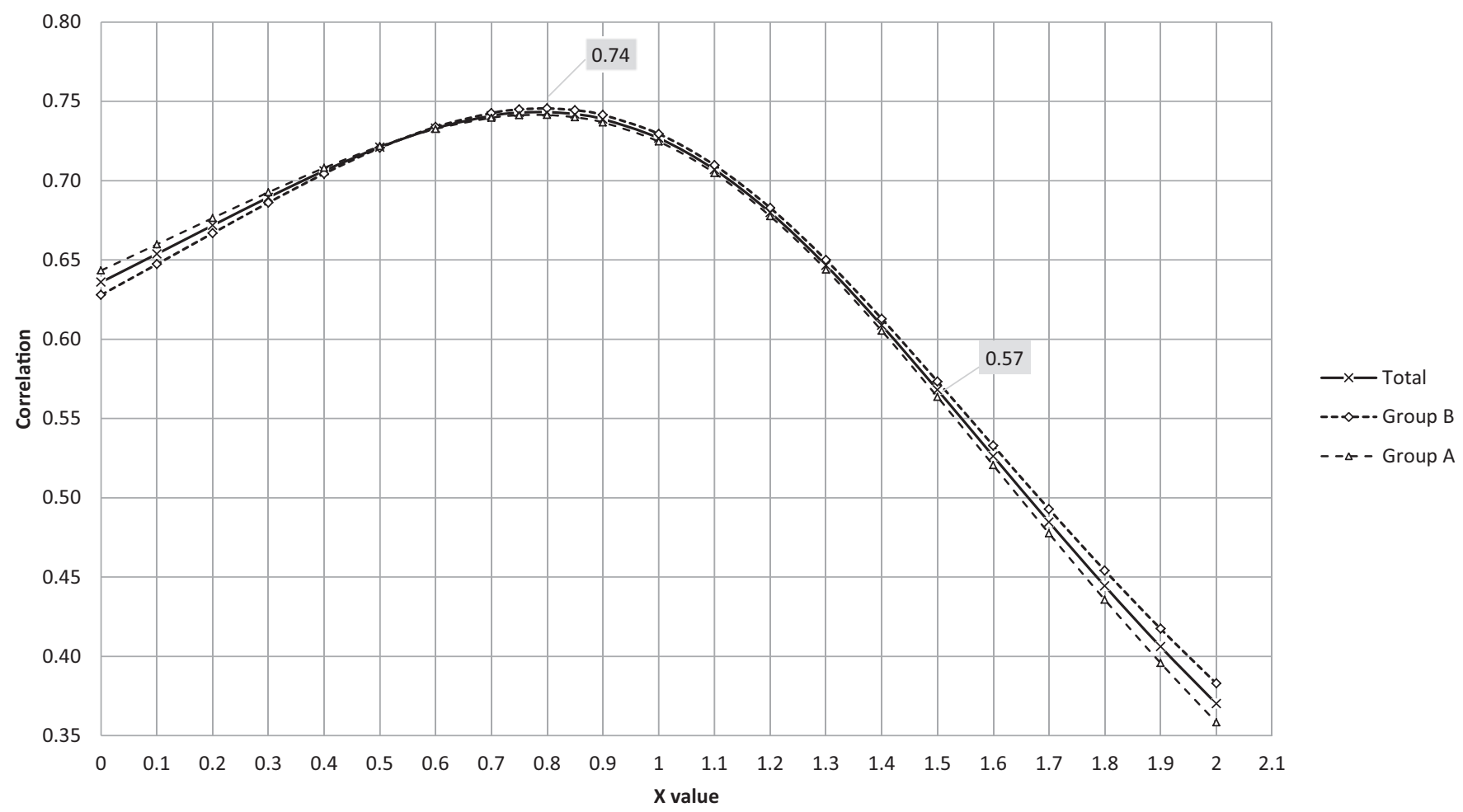

Figure 2. Calculated suggested body adiposity index for paediatrics $\left(\mathrm{BAI}_{\mathrm{p}}\right)$ with varying $x$ power term (abscissa).

using $\mathrm{BAI}_{\mathrm{p}}$ (mean bias of $-0.1 \%$; see Figure 3 ) compared to that provided with the original BAI (mean bias of $-10 \%$; see Figure 1). However, when genders were considered separately, the newly predicted $\% \mathrm{BF}$ over-estimated the $\% \mathrm{BF}$ in boys and under-estimated the \% BF in girls $(p<0.0001$ in each case). Furthermore, the limit of agreement between the predicted and the actual $\% \mathrm{BF}$ was quite wide [-9.1\%; $8.8 \%$ ].

\section{Discussion}

To our knowledge, this is the first study that aims to test the validity of body adiposity index (BAI) in children and to develop, if necessary, an appropriate BAI for paediatrics (i.e. $\mathrm{BAI}_{\mathrm{p}}$ ). Results of the current study indicate that the initial BAI, which was developed using an adult sample, is not valid 
Table 2. Summary of the models and cross-validation.

\begin{tabular}{|c|c|c|c|c|c|c|}
\hline & \multicolumn{3}{|c|}{ Characteristics of the model } & \multicolumn{3}{|c|}{ Cross-validity of the model } \\
\hline $\begin{array}{l}\text { Group A } \\
\quad(n=838)\end{array}$ & $Y=1.055 X-41.159$ & 0.550 & 4.641 & - & $\begin{array}{c}-0.267 \pm 4.479 \\
r=0.745^{* * *}\end{array}$ & $\begin{array}{c}0.123 \pm 4.567 \\
r=0.743^{* * *}\end{array}$ \\
\hline $\begin{array}{l}\text { Group B } \\
\quad(n=777)\end{array}$ & $Y=1.036 X-40.336$ & 0.556 & 4.478 & $\begin{array}{c}-0.111 \pm 4.646 \\
r=0.741 * * *\end{array}$ & - & $\begin{array}{c}0.123 \pm 4.567 \\
r=0.743^{* * *}\end{array}$ \\
\hline
\end{tabular}

$X$, BAIp: body adiposity index for paediatrics; $Y, \% \mathrm{BF}$ : percentage of body fat; SEE, Standard Error of Estimate.

***Denotes a significant relationship, $p<0.0001$

Figure 3. Bland and Altman pairwise comparison between the actual and the estimated percentage of body fat using the constructed body adiposity index for paediatrics $\left(\mathrm{BAI}_{\mathrm{p}}\right)$.

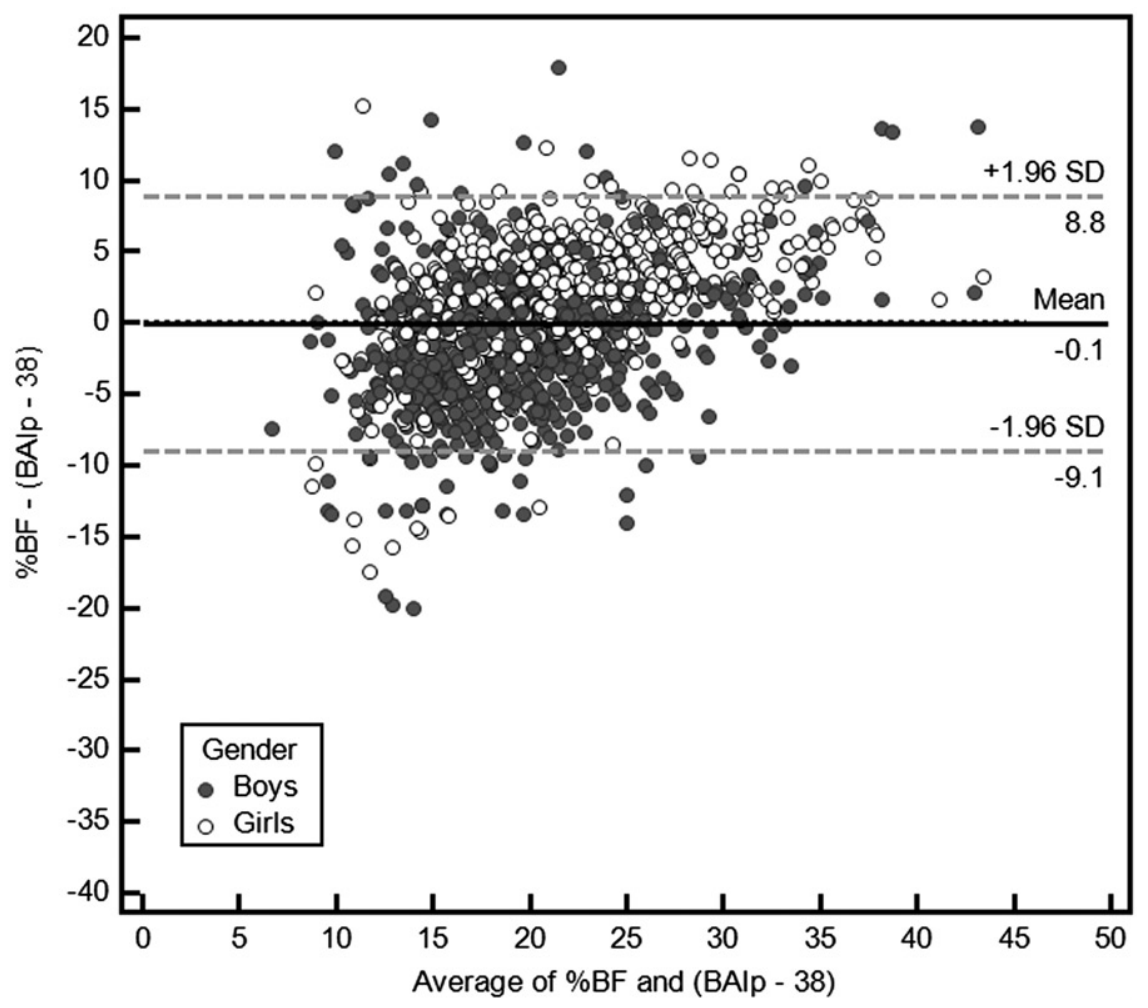

for children, as it may over-estimate the percentage of body fat $(\% \mathrm{BF})$ of young people. On the other hand, the replication of the methodological approach used by Bergman et al. (2011) showed its feasibility on a sample of children, since $\mathrm{BAI}_{\mathrm{p}}$ closely predicted the \%BF obtained with a foot-to-foot bioimpedance technique. Even if the bioelectrical impedance analysis may be less accurate than traditional, sophisticated laboratory techniques such as DEXA or MRI, studies comparing bioelectrical impedance methods with these well-established methods commonly report high $R^{2}$ values (0.91-0.97) (Mueller et al., 2004). Mueller et al. (2004) hypothesized that impedance may exhibit higher validity and usefulness in children in comparison to adults. With a former model of the Tanita body composition analyser, the TBF-300 M, correlations with DEXA of 0.92-0.95 have been reported in children (Hosking et al., 2006). However, because of a between-method systematic bias (i.e. under-estimation of fat mass with the Tanita foot-to-foot bioimpedance compared to DEXA), the authors have recommended the use of this method only in large scale epidemiological studies
(Hosking et al., 2006). Also, the device used in the present study was found in adults to be sufficiently valid for epidemiological studies rather than individual use (Lloret Linares et al., 2011). Unfortunately, to the best of our knowledge no such validation attempt has actually been made in children and youth with the Tanita BC-420 balance. To the contrary, data obtained with an earlier model, the BC-418, which was the last to be validated in the paediatric population, seems to converge in most weight categories with the $\% \mathrm{BF}$ obtained with BC-420 in the present study. Further studies are, however, required for the validation of the BC-420 Tanita balance. Thus, although the bio-electrical impedance analysis has the advantage over sophisticated techniques to be a rapid, inexpensive, portable, simple and non-invasive method of assessing the body composition of children, interpretation of the current results should be performed whilst bearing in mind this limitation.

The \%BF obtained in the current study with the footto-foot bioelectrical impedance was very close to values reported by earlier studies in a similar age group, using either 


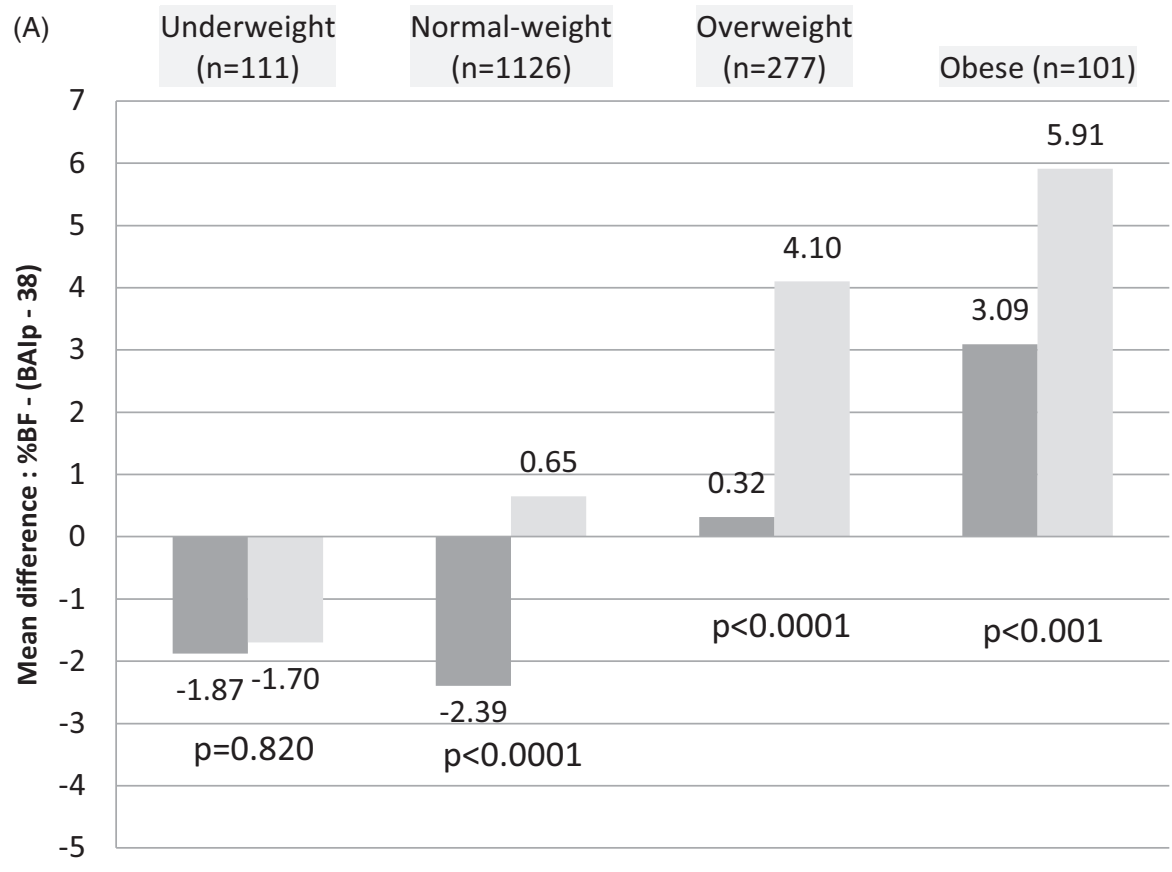

Boys ( $n=841)$

Girls (n=774)

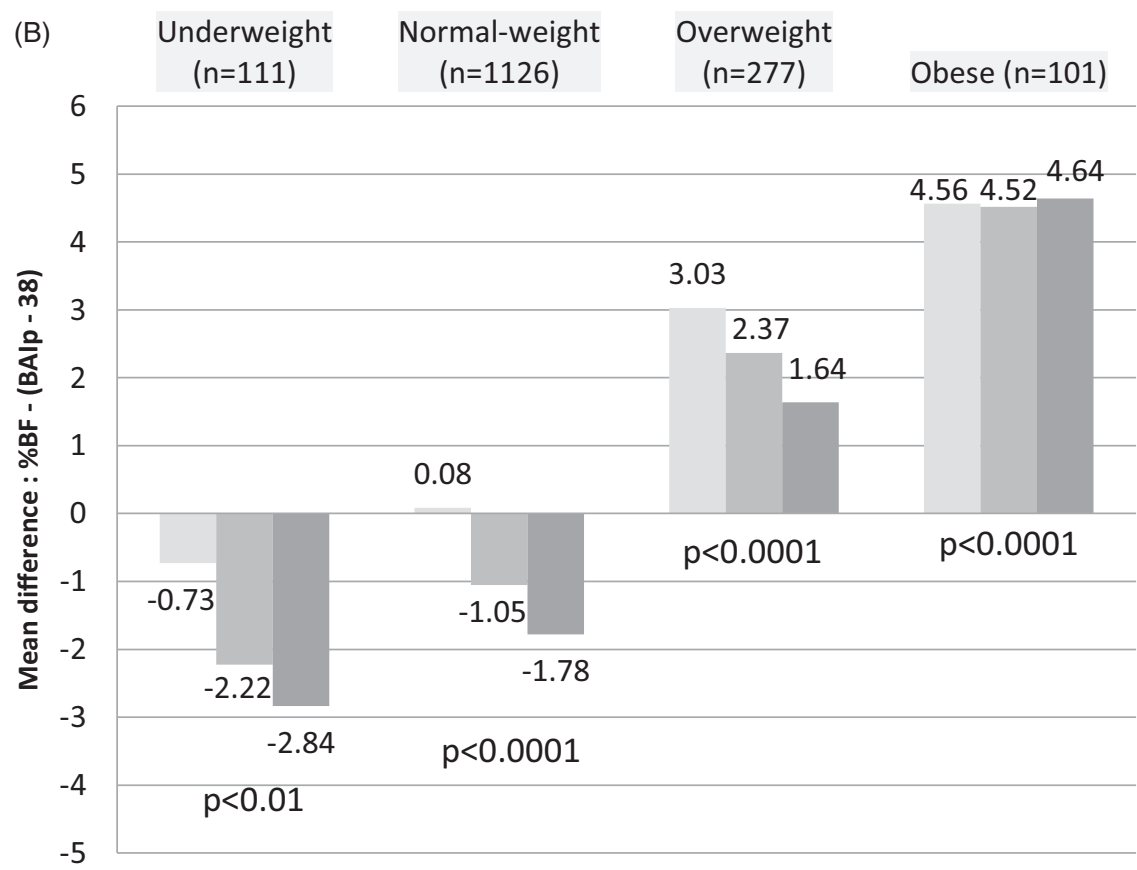

$$
\begin{aligned}
& {[5-7](n=489)} \\
& {[8-9](n=548)} \\
& {[10-12](n=578)}
\end{aligned}
$$

Figure 4. Mean difference in body fat percentage from bioimpedance and $\mathrm{BAI}_{\mathrm{p}}$ according to gender, age group and weight status by the IOTF classification.

another model of foot-to foot device or DEXA in children (Eisenmann et al., 2004; Hosking et al., 2006). For example, with bioimpedance, mean values of $\% \mathrm{BF}$ of $17.7 \%$ and $25.7 \%$ were found in boys and girls, respectively (Hosking et al., 2006), while the corresponding values in the current sample were $18.1 \%$ and $21.7 \%$. The mean $\% \mathrm{BF}$ for boys and girls in the present sample were even closer to those obtained by Hosking et al. (2006) with DEXA (i.e. $18.6 \%$ and $22.4 \%$ for boys and girls, respectively). Likewise, the estimated \%BF using $\mathrm{BAI}_{\mathrm{p}}$ (i.e. $19.7 \%$ and $20.2 \%$ for boys and girls, respectively), which slightly over-estimated the \% $\mathrm{BF}$ in boys and under-estimated the \% BF in girls, are in agreement with data obtained using DEXA in the literature (Eisenmann et al., 2004; Hosking et al., 2006). As the difference between the
$\% \mathrm{BF}$ obtained with bioimpedance and that predicted with $\mathrm{BAI}_{\mathrm{p}}$ was neither statistically significant nor clinically meaningful, one might assume that the use of $\mathrm{BAI}_{\mathrm{p}}$ may be an easier and valid way to obtain the $\% \mathrm{BF}$ in paediatrics. However, it should be acknowledged that, for the screening of adiposity at an individual level, the use of $\mathrm{BAI}_{\mathrm{p}}$ may be of limited value. Indeed, as displayed in Figure $4, \mathrm{BAI}_{\mathrm{p}}$ may both over- and under-estimate the $\% \mathrm{BF}$ when the weight status, gender and age category of children are taken into account. For instance, the $\mathrm{BAI}_{\mathrm{p}}$-based \%BF under-estimated the $\% \mathrm{BF}$ of underweight and normal weight children, but over-estimated that of overweight and obese children, with differences reaching statistical significance according to gender or age category of children. Such differences could 
result from the lack of agreement between a BMI-based classification system and the value of \%BF. It may also reflect the inaccuracy of the bioimpedance for estimating fat mass in children, especially at the extreme values of adiposity (i.e. very low and high adiposity) and this may have an effect upon $\mathrm{BAI}_{\mathrm{p}}$. In any case, $\mathrm{BAI}_{\mathrm{p}}$ appears not to be appropriate for the estimation of the \% $\mathrm{BF}$ at an individual level due to large errors in individual estimates as depicted by the wide limits of agreement in the Bland and Altman plot. In contrast, this $\mathrm{BAI}_{\mathrm{p}}$ may be helpful for large-scale epidemiological studies. Nevertheless, the gender-related difference in the estimation of \% BF using BAIp, which was apparent in all weight categories based on IOTF classification, should be considered as an indicator that BAI equation is a sex-specific one, at least in the paediatric population. This correcting factor that may improve the predictive value of $\mathrm{BAI}_{\mathrm{p}}$ (unshown data) may, however, weaken its attractiveness when compared to the unique and easy to use formulae of BMI. Thus, caution should be exercised in the use of the current BAIp due to this intentional simplification, which may result in an underestimation of \% BF in girls and an over-estimation in boys.

There are other limitations to the current study. The first is related to the a priori acceptance of the formalism by Bergman et al. (2011) without testing its underlying postulates among children, including (i) the use of anthropometric parameters that exhibited the strongest correlation with \% adiposity and (ii) the independence between the selected parameters. Because of important physiological differences between an adult and the growing body of a child, it may be pertinent to thoroughly consider these postulates. However, this may translate into the development of a different index, which cannot be named BAI, if the anthropometric characteristics associated with \% adiposity were found to be different in children. Therefore, further studies are required to test this alternative. The second limitation relates to the use of the foot-to-foot bioimpedance technique as a validation method. Because this technique is not considered as the gold standard for body fatness, additional studies using DEXA or MRI are needed to substantiate the current findings.

Body adiposity index (BAI) is not able to predict \% BF in children and indeed over-estimates \%BF. In contrast, its equivalence in paediatric populations (i.e. $\mathrm{BAI}_{\mathrm{p}}$ ) represents a new index for estimating the body fatness of children, with acceptable accuracy compared with a bioimpedance measure. In its current form, this index may be valid for large-scale epidemiological studies, but it may not be pertinent for screening at an individual level. Further studies are required to improve its predictive ability at both group and individual levels and to compare its diagnostic performance to that of BMI.

\section{Acknowledgements}

We are indebted to children (School districts of the North) and their parents for nice participation. We would also like to thank the city councils of Villeneuve d'Ascq and Maubeuge Val de Sambre for their support of the studies.

\section{Declaration of interest}

The authors report no conflicts of interest. The authors alone are responsible for the content and writing of the paper.

\section{References}

Bergman RN, Stefanovski D, Buchanan TA, Sumner AE, Reynolds JC, Sebring NG, Xiang AH, Watanabe RM. 2011. A better index of body adiposity. Obesity (Silver Spring) 19:1083-1089.

Bland JM, Altman DG. 1999. Measuring agreement in method comparison studies. Stat Methods Med Res 8:135-160.

Browning LM, Hsieh SD, Ashwell M. 2010. A systematic review of waist-to-height ratio as a screening tool for the prediction of cardiovascular disease and diabetes: 0.5 could be a suitable global boundary value. Nutr Res Rev 23:247-269.

Cole TJ, Bellizi MC, Flegal KM, Dietz WH. 2000. Establishing a standard definition of childhood obesity worldwide: International survey. Br Med J 320:1-6.

De Onis M, Onyango AW, Borghi E, Siyam A, Nishida C, Siekmann J. 2007. Development of a WHO growth reference for school-aged children and adolescents. Bull World Health Organ 85:660-667.

Eisenmann JC, Heelan KA, Welk G. 2004. Assessing body composition among 3- to 8-year-old children: anthropometry, BIA, and DXA. Obes Res 12:1633-1640.

Elisha B, Rabasa-Lhoret R, Messier V, Abdulnour J, Karelis AD. 2013. Relationship between the body adiposity index and cardiometabolic risk factors in obese postmenopausal women. Eur J Nutr 51:145-151.

Freedman DS, Thornton J, Pi-Sunyer FX, Heymsfield SB, Wang J, Pierson JRN, Blanck HM, Gallagher D. 2012. The body adiposity index (hip circumference $\div$ height(1.5)) is not a more accurate measure of adiposity than is BMI, waist circumference, or hip circumference. Obesity (Silver Spring) 20:2438-2444.

Gillum RF. 1999. Distribution of waist-to-hip ratio, other indices of body fat distribution and obesity and associations with HDL cholesterol in children and young adults aged 4-19 years: The Third National Health and Nutrition Examination Survey. Int J Obes Relat Metab Disord 23: $556-563$.

Godoy-Matos AF, Moreira RO, Valerio CM, Mory PB, Moises RS. 2012. A new method for body fat evaluation, body adiposity index, is useful in women with familial partial lipodystrophy. Obesity (Silver Spring) 20:440-443.

Hall DM, Cole TJ. 2006. What use is the BMI? Arch Dis Child 91: 283-286.

Han JC, Lawlor DA, Kimm SYS. 2010. Childhood obesity. Lancet 375: 1737-1748.

Hosking J, Metcalf BS, Jeffery AN, Voss LD, Wilkin TJ. 2006. Validation of foot-to-foot bioelectrical impedance analysis with dual-energy X-ray absorptiometry in the assessment of body composition in young children: the EarlyBird cohort. Br J Nutr 96: $1163-1168$

Hung CS, Yang CY, Hsieh HJ, Wei JN, Ma WY, Li HY. 2012. BMI correlates better to visceral fat and insulin sensitivity than BAI. Obesity (Silver Spring) 20:1141.

Lin LI. 1989. A concordance correlation coefficient to evaluate reproducibility. Biometrics 45:255-268.

Lloret Linares C, Ciangura C, Bouillot JL, Coupaye M, Declèves X, Poitou C, Basdevant A, Oppert JM. 2011. Validity of leg-to-leg bioelectrical impedance analysis to estimate body fat in obesity. Obes Surg 21:917-922.

Lobstein T, Baur L, Uauy R. 2004. Obesity in children and young people: a crisis in public health. Obesity Rev 5:4-104.

Lohmann TG, Roche AF, Martorell R. 1988. Anthropometric standardization reference manual. Champaign, IL: Human Kinetics.

López AA, Cespedes ML, Vicente T, Tomas M, Bennasar-Veny M, Tauler P, Aguilo A. 2012. Body adiposity index utilization in a Spanish Mediterranean population: comparison with the body mass index. PLoS One 7:e35281.

McCarthy HD. 2006. Body fat measurements in children as predictors for the metabolic syndrome: focus on waist circumference. Proc Nutr Soc 65:385-392.

McCarthy HD, Cole TJ, Fry T, Jebb SA, Prentice AM. 2006. Body fat reference curves for children. Int J Obes (Lond) 30:598-602.

Mueller WH, Harrist RB, Doyle SR, Labather DR. 2004. Percentiles of body composition from bioelectrical impedance and body measurements in US adolescents 8-17 years old: Project Heartbeat! Am J Human Biol 16:135-150.

Neovius M, Linné Y, Barkeling B, Rössner S. 2004. Discrepancies between classification systems of childhood obesity. Obes Rev 5: $105-114$ 
Olds T, Maher C, Zumin S, Péneau S, Lioret S, Castetbon K, Bellisle F, et al. 2011. Evidence that the prevalence of childhood overweight is plateauing: data from nine countries. Int J Pediatr Obes 6:342-360.

OMS. 2003. Obésité: prévention et prise en charge de l'épidémie mondiale. Rapport d'une consultation de l'Organisation Mondiale de la Santé (OMS). Geneva: World Health Organization (WHO).

Schulze MB, Thorand B, Fritsche A, Häring HU, Schick F, Zierer A, Rathmann W, Kröger J, et al. 2012. Body adiposity index, body fat content and incidence of type 2 diabetes. Diabetologia 55: $1660-1667$.

Serdula MK, Ivery D, Coates RJ, Freedman DS, Williamson DF, Byers T. 1993. Do obese children become obese adults? A review of the literature. Prev Med 22:167-177.
Snijder MB, Nicolaou M, Van Valkengoed IG, Brewster LM, Stronks K. 2012. Newly proposed Body Adiposity Index (BAI) by Bergman et al. is not strongly related to cardiovascular health risk. Obesity (Silver Spring) 20:1138-1139.

Taylor RW, Williams SM, Grant AM, Taylor BJ, Goulding A. 2011. Predictive ability of waist-to-height in relation to adiposity in children is not improved with age and sex-specific values. Obesity (Silver Spring) 19:1062-1068.

Whitaker RC, Wright JA, Pepe MS, Seidel KD, Dietz WH. 1997. Predicting obesity in young adulthood from childhood and parental obesity. N Engl J Med 337:869-873.

WHO. 2009. Global health risks: mortality and burden of disease attributable to selected major risks. Geneva: World Health Organization. 
Copyright of Annals of Human Biology is the property of Taylor \& Francis Ltd and its content may not be copied or emailed to multiple sites or posted to a listserv without the copyright holder's express written permission. However, users may print, download, or email articles for individual use. 